\title{
Perceptions of the Inpatient Training Experience: A Nationwide Survey of Gastroenterology Program Directors and Fellows
}

\author{
Navin L. Kumar ${ }^{1,2} \cdot$ Molly L. Perencevich ${ }^{1,2} \cdot$ Jerry S. Trier $^{1,2}$
}

Received: 31 March 2017 / Accepted: 7 August 2017/Published online: 16 August 2017

(C) Springer Science+Business Media, LLC 2017

\begin{abstract}
Background Inpatient training is a key component of gastroenterology (GI) fellowship programs nationwide, yet little is known about perceptions of the inpatient training experience.

Aim To compare the content, objectives and quality of the inpatient training experience as perceived by program directors (PD) and fellows in US ACGME-accredited GI fellowship programs.

Methods We conducted a nationwide, online-based survey of GI PDs and fellows at the conclusion of the 2016 academic year. We queried participants about (1) the current models of inpatient training, (2) the content, objectives, and quality of the inpatient training experience, and (3) the frequency and quality of educational activities on the inpatient service. We analyzed five-point Likert items and rank assessments as continuous variables by an independent $t$ test and compared proportions using the Chi-square test.

Results Survey response rate was $48.4 \%$ (75/155) for PDs and a total of 194 fellows completed the survey, with both groups reporting the general GI consult team $(>90 \%)$ as the primary model of inpatient training. PDs and fellows agreed on the ranking of all queried responsibilities of the inpatient fellow to develop during the inpatient service. However, fellows indicated that attendings spent less time teaching and provided less formal feedback than that
\end{abstract}

Navin L. Kumar

nlkumar@partners.org

1 Division of Gastroenterology, Hepatology and Endoscopy, Brigham and Women's Hospital, 75 Francis Street, Boston, MA 02115, USA

2 Harvard Medical School, Boston, MA, USA perceived by PDs $(p<0.0001)$. PDs rated the overall quality of the inpatient training experience $(p<0.0001)$ and education on the wards $(p=0.0003)$ as better than overall ratings by fellows.

Conclusion Although GI fellows and PDs agree on the importance of specific fellow responsibilities on the inpatient service, fellows report experiencing less teaching and feedback from attendings than that perceived by PDs. Committing more time to education and assessment may improve fellows' perceptions of the inpatient training experience.

Keywords Fellowship · Training · Education · Assessment

\begin{tabular}{ll}
\multicolumn{2}{l}{ Abbreviations } \\
ACGME & Accreditation Counsel for Graduate Medical \\
& Education \\
GI & Gastroenterology \\
PD & Program director \\
AMA & American Medical Association \\
ACG & American College of Gastroenterology \\
REDCap & Research Electronic Data Capture \\
SD & Standard deviation
\end{tabular}

\section{Introduction}

Inpatient care of patients with gastrointestinal disease is a key component of Accreditation Counsel for Graduate Medical Education (ACGME)-accredited gastroenterology (GI) fellowship training programs in the USA. The GI core curriculum sets a minimum threshold of 18 months of clinical training experience for all GI fellows, the majority of which is fulfilled by inpatient service time [1]. In addition to the training experience derived from direct 
patient care, the core curriculum also specifies the importance of educational conferences as well as faculty dedicated to teaching as critical aspects of a GI fellowship program.

Recent studies of the balance between workload and educational activities among pediatric and medical residents provide evidence that increased patient care activities reduce participation in structured learning activities [2, 3]. It is likely that a balance between patient workload and involvement in learning activities also applies to gastroenterology trainees [4].

Although prior studies have surveyed both GI program directors (PD) and fellows on specific educational content within fellowship programs, little is known about the perceptions of the inpatient training experience as a whole [5-8]. The aims of this study were thus to (1) survey the current models of inpatient training, (2) assess the content, objectives and quality of the inpatient training experience, and (3) evaluate the frequency and quality of educational activities on the inpatient service, as perceived by PDs and fellows in US ACGME-accredited GI fellowship programs.

\section{Methods}

\section{Survey Instruments}

For this two-phased study, two survey instruments were created-one specific for PDs and one specific for gastroenterology fellows. The content of the surveys was influenced by the GI core curriculum and interviews with experts in gastroenterology fellowship training. Pilot testing of the PD survey was performed by current and past program directors of the gastroenterology fellowship at the Brigham and Women's Hospital, and similarly by current gastroenterology fellows at the same institution for the fellow survey.

The PD survey (Appendix 1) and fellow survey (Appendix 2) queried participants about (1) the current models of inpatient training, (2) the perceived importance of specific fellow responsibilities and skill development while on the inpatient service, (3) the frequency and quality of educational activities (including attending feedback) during inpatient rotations, (4) the possibility of fellows feeling overworked during inpatient rotations, and (5) the overall quality of the inpatient training experience. Lastly, respondents were given the option to freetext any thoughts they had on improving the inpatient training experience at the end of the survey.

\section{Study Cohort}

The American Medical Association (AMA) Residency and Fellowship database was used to identify all 3-year gastroenterology fellowship programs in the US accredited by the ACGME [9]. Contact information for PDs and program coordinators was obtained from the AMA database and cross-referenced with the American College of Gastroenterology (ACG) database of gastroenterology fellowship programs [10]. A total of 168 gastroenterology fellowship programs were identified through this process. An introductory email was sent to all PDs or program coordinators (if the PD's email was not available) outlining the study and providing the opportunity to withdraw from the study prior to distribution of the surveys. Three programs requested to be excluded, five programs were in periods of transition without current fellows, four PDs were not available during the survey period, and one program did not have contact information. A total of 155 ACGMEaccredited gastroenterology fellowship programs were thus considered for the study.

\section{Survey Distribution}

For the first phase of the study, a unique link with the PD survey was electronically sent to each PD (or program coordinator) in March 2016 using the Research Electronic Data Capture (REDCap) web application, which is a secure web application for building and managing online surveys [11]. The REDCap application maintained a $\log$ of all responders and non-responders of the PD survey. A personalized email reminder was sent to each non-responder at two weeks and again at three weeks after the initial survey link was delivered.

For the second phase of the study, an introductory email outlining the fellow survey was sent to the program coordinators in April 2016 and requested their participation in forwarding the public REDCap survey link to their gastroenterology fellows (the majority of programs did not disclose individual fellow email addresses). The initial survey request was electronically sent to the program coordinators one week after the introductory email with a link to the fellow survey and a request for the survey to be forwarded to their fellows. This was repeated for each of the subsequent two weeks. All data from both phases of the study were anonymously logged by the REDCap software.

\section{Statistical Analysis}

Means and standard deviations were used to describe continuous variables and counts and percentages for categorical variables. Likert and rank item responses were analyzed as continuous variables, as conventionally reported [12]. PD and fellow responses were compared using an independent $t$ test for continuous variables and the Chi-squared test for proportions. For the optional comments left by respondents, a grounded theory approach 
(inductive process of generating broader insights from qualitative data) was used to identify themes for improving the inpatient training experience [13]. $P$ values less than 0.05 were considered significant. All analyses were conducted using JMP Pro version 12 (SAS Institute, Cary, NC). This study was reviewed and deemed exempt by the institutional review board of Partner's Healthcare.

\section{Results}

\section{Baseline Characteristics}

Program characteristics and demographics reported by PDs and fellows are shown in Table 1. Seventy-five PDs (48.4\%) responded completely to the survey. PDs noted the clinical track as the most common track for fellows
$(93.3 \%)$ and the basic science research track (22.7\%) as the least common. PDs cited the academic medical center as the primary inpatient site for the fellowship (74.7\%). A general GI consult team was identified as the primary inpatient service type $(92.0 \%)$.

A total of 194 fellows responded completely to the survey. The majority of fellow respondents were male $(65.5 \%)$, and there was representation from each year of training (1st years-37.6\%, 2nd years-32.5\%, and 3rd years-29.9\%). Fellows reported an average of 11.3 (SD 4.41) fellows in their respective fellowship programs. The majority of fellows were in clinical tracks $(80.9 \%)$ for their fellowship, whereas the least common fellowship track was the basic science research track (3.1\%). Fellows also reported the academic medical center as the primary inpatient site of training $(86.6 \%)$ and the general GI consult team as the primary inpatient service type $(93.8 \%)$.
Table 1 Program characteristics and demographics reported by program directors and fellows

\begin{tabular}{lll}
\hline Characteristic & Program directors & Fellows \\
\hline Number & 75 & 194 \\
Gender (fellows only) & & \\
Male & - & $127(65.5 \%)$ \\
Female & - & $67(34.5 \%)$ \\
Year of fellowship training (fellows only) & & \\
1st year & - & $73(37.6 \%)$ \\
2nd year & - & $63(32.5 \%)$ \\
3rd year & - & $58(29.9 \%)$ \\
Fellowship track (multiple allowed for PDs only) & & \\
Clinical track & $70(93.3 \%)$ & $157(80.9 \%)$ \\
Research (clinical) track & $20(26.7 \%)$ & $31(16.0 \%)$ \\
Research (basic science) track & $17(22.7 \%)$ & $6(3.1 \%)$ \\
Inpatient training sites (multiple allowed for PDs and fellows) & \\
Academic medical center & $73(97.3 \%)^{\mathrm{a}}$ & $186(95.9 \%)^{\mathrm{b}}$ \\
VA & $36(48.0 \%)$ & $115(59.3 \%)$ \\
Public & $16(21.3 \%)$ & $74(38.1 \%)$ \\
Community & $29(38.7 \%)$ & $78(40.2 \%)$ \\
Military & $3(4.0 \%)$ & $7(3.6 \%)$ \\
HMO & $0(0.0 \%)$ & $2(1.0 \%)$ \\
Other & $1(1.3 \%)$ & $2(1.0 \%)$ \\
Inpatient service type (multiple allowed for PDs and fellows) & $193(99.5 \%)^{\mathrm{d}}$ \\
General GI consult team & $75(100.0 \%)^{\mathrm{c}}$ & $69(35.6 \%)$ \\
Disease-specific GI consult team & $48(64.0 \%)$ & \\
General GI admitting team & $9(12.0 \%)$ & \\
Disease-specific GI admitting team & $13(17.3 \%)$ & \\
\hline & & \\
& &
\end{tabular}

${ }^{a}$ Primary inpatient training site per PDs $(74.7 \%)$

b Primary inpatient training site per fellows $(86.6 \%)$

c Primary inpatient service type per PDs $(92.0 \%)$

${ }^{d}$ Primary inpatient service type per fellows $(93.8 \%)$ 


\section{Perceived Importance of Specific Fellow \\ Responsibilities on the Inpatient Service}

PDs and fellows were asked to rank from most important (1) to least important (6) the following inpatient responsibilities to ensure proper running of the inpatient service: lead clinical rounds, perform endoscopic procedures, complete inpatient documentation, organize teaching, communicate with outpatient GI providers, and schedule outpatient GI follow-up appointments. PDs and fellows agreed on the ranking for all six of these fellow responsibilities (Table 2). Specifically, leading clinical rounds, performing endoscopy, and completing inpatient documentation were reported as the most important tasks by PDs and fellows. In contrast, PDs and fellows rated the responsibilities of arranging for outpatient follow-up and communicating with outpatient GI providers as the least important.

\section{Frequency and Quality of Educational Activities}

On a 5-point Likert scale $(1=100 \%$ of time, to $5=0 \%$ of time), PDs and fellows both noted that a fellow returns to the bedside with the attending after evaluating a new consult between 75 and $100 \%$ of the time ( 1.75 vs. $1.90, p=0.226$ ). The two groups also agreed that fellows review relevant inpatient radiology studies with a radiologist between 50 and $75 \%$ of the time (2.64 vs. $2.69, p=0.720$ ), but PDs indicated that fellows reviewed relevant inpatient pathology specimens with a pathologist (2.99 vs. $3.53, p=0.001)$ and attended academic conferences (1.37 vs. $1.66, p=0.004)$ more often than that reported by fellows. At the conclusion of inpatient rotations, PDs also reported that attendings provided formal feedback more often than that perceived by fellows (2.59 vs. $3.35, p<0.0001)$ (Fig. 1).

Similarly, on a 5-point Likert scale $(1=\geq 60 \mathrm{~min}$, to $5=0 \mathrm{~min}$ ), PDs indicated that attendings set aside more time for teaching on the inpatient service than that perceived by fellows (2.03 vs. 2.96, $p<0.0001)$ (Fig. 1). When asked about time spent by fellows teaching other members of the team, PDs again perceived that more time was dedicated to teaching than that reported by fellows (2.35 vs. $2.88, p<0.0001)$.

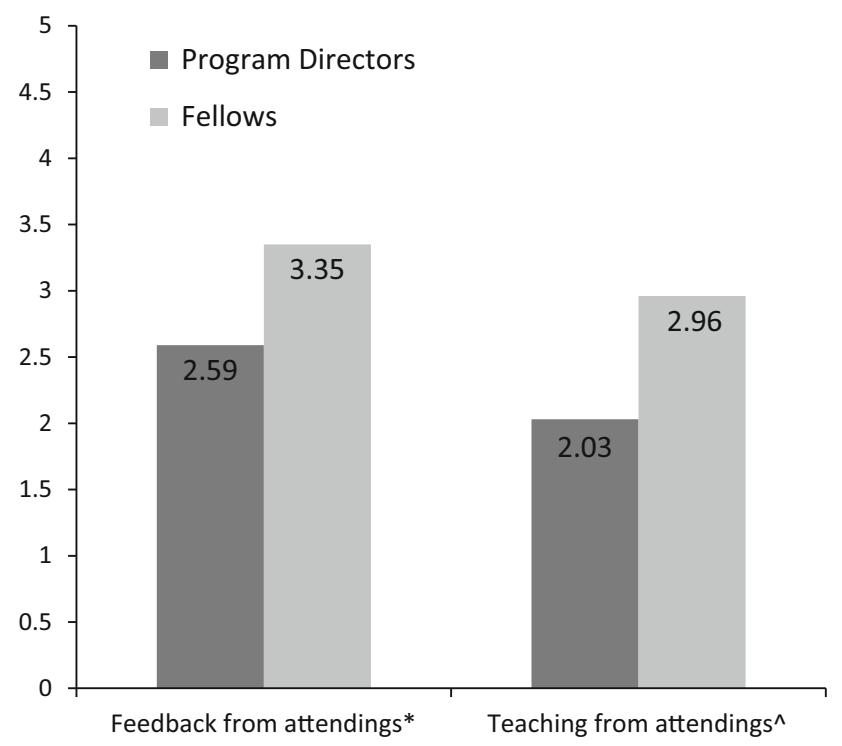

*Based on 5-point Likert scale ( $1=100 \%$ of time, $2=75 \%$ of time, $3=50 \%$ of time, $4=25 \%$ of time, $0=0 \%$ of time)

${ }^{\wedge}$ Based on 5-point Likert $\geq-60$ minutes/day, $3=15-30$ minutes/day, $4=<15$ minutes/day, $5=0$ minutes/day)

Fig. 1 Reported frequency of attending-led feedback and teaching for fellows

\section{Perceptions of Clinical Workload on the Inpatient Service}

When asked about the frequency of duty hour violations for the inpatient fellow (5-point Likert scale: $1=100 \%$ of time, to $5=0 \%$ of time), PDs and fellows both reported these events as rare, although PDs felt that they occurred slightly less often than fellows ( 4.85 vs. $4.65, p=0.005$ ). In terms of the inpatient fellow feeling overworked, PDs reported this occurred less frequently than that reported by fellows (4.01 vs. $3.51, p<0.0001$ ), with PDs estimating $25 \%$ of the time, whereas fellows felt it was somewhere between 25 and $50 \%$.

\section{Overall Quality of the Inpatient Training Experience}

PDs rated the overall quality of the inpatient training experience and educational components as better than the
Table 2 Reported importance of fellow responsibilities on the inpatient service (ranking from 1 to 6 in descending order of importance)

\begin{tabular}{llll}
\hline & $\begin{array}{l}\text { Program director (mean, SD) } \\
N=75\end{array}$ & $\begin{array}{l}\text { Fellow (mean, SD) } \\
N=194\end{array}$ & $P$ value \\
\hline Lead clinical rounds & $2.80(1.72)$ & $2.85(1.69)$ & 0.828 \\
Perform endoscopic procedures & $2.80(1.41)$ & $2.93(1.64)$ & 0.510 \\
Complete inpatient documentation & $2.89(1.67)$ & $2.88(1.68)$ & 0.941 \\
Organize teaching & $3.85(1.32)$ & $3.84(1.17)$ & 0.940 \\
Communicate with outpatient GI provider & $4.00(1.48)$ & $4.13(1.56)$ & 0.529 \\
Arrange for outpatient follow-up & $4.65(1.72)$ & $4.37(1.73)$ & 0.230 \\
\hline
\end{tabular}


Table 3 Reported overall quality of the inpatient training experience and educational components (Likert scale: $1=$ very good, $2=$ good,

$3=$ acceptable, $4=$ poor,

$5=$ very poor)

\begin{tabular}{lllc}
\hline & $\begin{array}{l}\text { Program director (mean, SD) } \\
N=75\end{array}$ & $\begin{array}{l}\text { Fellow (mean, SD) } \\
N=194\end{array}$ & $P$ value \\
\hline Education on the wards & $1.85(0.77)$ & $2.28(1.01)$ & 0.0003 \\
Education from academic conferences & $1.49(0.64)$ & $1.95(0.85)$ & $<0.0001$ \\
Attending feedback & $2.27(0.88)$ & $2.55(1.00)$ & 0.026 \\
Overall inpatient training experience & $1.15(0.36)$ & $1.47(0.60)$ & $<0.0001$ \\
\hline
\end{tabular}

ratings provided by fellows (Table 3). On a 5-point Likert scale $(1=$ very good, to $5=$ very poor $)$, PDs felt that education on the wards (1.85 vs. $2.28, p=0.0003)$, education from academic conferences (1.49 vs. 1.95, $p<0.0001)$, and attending feedback $(2.27$ vs. 2.55 , $p=0.026$ ) were of a higher quality than that perceived by fellows. PDs also rated the overall inpatient training experience as higher in quality than that reported by fellows $(1.15$ vs. $1.47, p<0.0001)$. Of note, the majority of fellows felt that the general GI consult team was the preferred model for inpatient training (70.6\% strongly agreed).

\section{Participant Comments}

A total of 28 PDs (37.3\% of PD respondents) submitted optional comments at the end of the survey (Table 4). PDs cited the need to lighten the outpatient workload of the inpatient attending such that he or she can fully dedicate him/ herself to the inpatient team. PDs also proposed an increase in mid-level providers (i.e., physician assistants or nurse practitioners) to ease the documentation and scheduling burden on the fellows. Lastly, PDs identified the need for inpatient attendings to lead educational activities on the inpatient service, including more direct observation of fellows' clinical care as well as didactic teaching for the inpatient team.

A total of 42 fellows (21.6\% of fellow respondents) submitted optional comments at the end of the survey (Table 4). Fellows frequently requested more formal teaching from attendings, such as faculty-led bedside rounds or prepared didactics. Fellows also commented on the need for increased frequency and quality of attending feedback. On a programmatic level, fellows highlighted the need for improved balance between clinical duties and educational activities by limiting inpatient workload.

\section{Discussion}

In this nationwide survey of ACGME-accredited GI program directors and fellows about the inpatient training experience, both groups agreed on the relative importance of specific responsibilities on the inpatient service. However, fellows reported experiencing less teaching and feedback from attendings than that perceived by PDs.
Fellows also rated the overall quality of the inpatient training experience as lower than the ratings given by PDs.

The consensus between PDs and fellows on the importance of specific fellow responsibilities reflects a mutual understanding of the objectives of the inpatient rotation and the level of training of fellows. Leadership and procedural skills were prioritized by both groups as critical to the proper running of the inpatient service, whereas more administrative tasks such as scheduling outpatient appointments were considered as less important.

An important finding of this study was that fellows reported receiving less teaching and structured feedback from attendings than that perceived by PDs. Indeed, 52.4\% of comments submitted by fellows focused on issues related to teaching and feedback from their attendings. Further analysis of the comments section of the survey reveals possible explanations for this occurrence. First, the inpatient attending often must balance both outpatient and inpatient obligations, which leaves little time to dedicate to teaching on the wards. Second, in the current system there is a lack of incentive (e.g., financial or promotion-based) for faculty to teach. A third additional reason may be the lack of formal training of faculty in teaching and delivering effective feedback, which is not unique to the field of gastroenterology. In fact, most faculty in medicine receive little or no training in how to be effective teachers, including how to provide helpful feedback to trainees [14, 15].

Another important finding of this study was that fellows reported feeling overworked during their inpatient rotations at a significantly higher rate than that reported by PDs. Prior literature from the fields of pediatric and internal medicine residency has shown that increased perceived workload is associated with decreases in perceived learning, including objective evidence of decreased attendance at academic conference [2-4]. Thus, in addition to less teaching and structured feedback from faculty, an imbalance between fellow workload and time for educational activities likely also contributed to the lower ratings for education on the wards given by fellows as compared with PDs.

To our knowledge, there are no previously published studies on the inpatient training experience as perceived by PDs and fellows, despite the significant role that the inpatient rotation occupies in GI fellowship programs. A similarly designed study of both PDs and fellows 
Table 4 Themes for improving the inpatient training experience among GI program directors and fellows

\begin{tabular}{|c|c|}
\hline Theme for improvement & Representative quote(s) \\
\hline \multicolumn{2}{|l|}{ Program directors } \\
\hline Protect inpatient attending schedule & $\begin{array}{l}\text { "Attending physicians would need to be freed of other clinical responsibilities so they can devote } \\
\text { more time to teaching." } \\
\text { "Free up attendings' time for bedside rounds and didactics on daily as needed basis..." } \\
\text { "Need the attendings on service to be given the appropriate amount of free time to perform patient } \\
\text { care, endoscopy and teaching..." }\end{array}$ \\
\hline $\begin{array}{l}\text { Utilize mid-level providers to ease the } \\
\text { inpatient fellow workload }\end{array}$ & $\begin{array}{l}\text { "Have mid-level providers do more of the paperwork and scheduling." } \\
\text { "Use physician extenders to reduce documentation needs and scheduling headaches." }\end{array}$ \\
\hline $\begin{array}{l}\text { Increase attending-directed educational } \\
\text { activities }\end{array}$ & $\begin{array}{l}\text { "Attendings need to directly observe fellows take histories and do physicals on a regular basis to } \\
\text { ensure that they acquire the expertise of a sound gastroenterologist." } \\
\text { "Attendings provide more short teaching sessions." }\end{array}$ \\
\hline \multicolumn{2}{|l|}{ Fellows } \\
\hline Increase formal teaching from attendings & $\begin{array}{l}\text { "More attending-led bedside teaching or prepared lectures..." } \\
\text { "I would appreciate more didactics from our faculty" }\end{array}$ \\
\hline $\begin{array}{l}\text { Increase structured feedback from } \\
\text { attendings }\end{array}$ & $\begin{array}{l}\text { "More specific feedback to fellows." } \\
\text { "I value end-of-rotation constructive feedback" } \\
\text { "There needs to be effective feedback from attendings..." }\end{array}$ \\
\hline $\begin{array}{l}\text { Achieve balance between patient care and } \\
\text { education }\end{array}$ & $\begin{array}{l}\text { "There is always a balance between clinical duties and teaching..." } \\
\text { "...education is not balanced with the service responsibility" } \\
\text { "Service obligations overwhelm any time for teaching." } \\
\text { "Limit the number of new consults in a day per fellow..." }\end{array}$ \\
\hline
\end{tabular}

investigated the status of competency-based education in endoscopy training [16]. As in our study, the authors also found a difference in the perceptions of training, with PDs rating the overall quality of their endoscopic training and assessment as better than that assessed by fellows. Outside of gastroenterology, a recent survey study of nephrology program directors evaluated some components of inpatient training for nephrology fellows [17]. While quantifying inpatient service characteristics such as service type, patient census and call responsibilities, the study did not query PDs on such items as the relative importance of specific fellow responsibilities nor the quality of education and also did not include fellows in the study sample.

There are some important limitations to consider in this study. For one, the response rate of program directors was less than ideal at $48.4 \%$. However, this rate is superior to the $30 \%$ response rate of most internet-based survey studies [18]. Second, the response rate for fellows could not be reliably calculated as the vast majority of programs did not provide specific fellow email addresses and thus a public survey link had to be used, without confirmation of its receipt by fellows. Third, it is possible that respondents from both groups were more interested in the state of inpatient training (selection bias). Lastly, as a result of protecting anonymity for each respondent, it was not possible to assess intra-program concordance between PDs and fellows. However, we do know that PDs and fellows originated from similar programs, with both groups citing the general GI consult team as the primary inpatient service type and the academic medical center as the primary inpatient site.

In conclusion, gastroenterology program directors and fellows agreed on the relative importance of specific fellow responsibilities on the inpatient service. However, fellows reported receiving less teaching and feedback from faculty than that perceived by PDs, which may explain fellows' lower overall rating of the inpatient training experience. Moving forward, it will be important for fellowship programs to query their fellows on the quality and frequency of attending-led teaching and feedback for fellows on the inpatient service. In addition, there needs to be more emphasis on protecting time for attendings to teach on the wards as well as faculty development on strategies of effective teaching and assessment. Further research should also focus on strategies to protect the delicate balance between inpatient clinical duties and education for fellows.

Author's contribution NLK designed the survey instruments, conducted the statistical analysis, and wrote the manuscript. MLP edited the survey instruments and manuscript. JST conceived the idea and edited the survey instruments and manuscript. All authors approved the final manuscript.

\section{Compliance with ethical standards}

Conflict of interest There are no potential personal or financial conflicts of interest to disclose. 


\section{Appendix 1}

Confidential

\section{Gastroenterology Fellow Inpatient Training: Program Director Survey

Please complete the survey below.

Thank you!

GI FELLOWSHIP PROGRAM INFORMATION: The following questions apply to fellows in your ACGME-accredited fellowship program. Please do not include any advanced fellows (e.g. advanced endoscopy, IBD fellows, etc.) or other fellows in non-ACGME positions (e.g. hepatology fellows) when answering these questions.

1) How many GI fellows (years 1-3) are in your ACGME-accredited fellowship program currently?

2) How many fellowship tracks are in your program? Please select all that apply.

$\square$ Clinical (not research-focused)

$\square$ Research (clinical)

$\square$ Research (basic science)

For each fellowship track in your program, how much time do fellows spend on the inpatient service(s) during their fellowship?

3) Clinical (not research-focused)

0-6 mths 6-12 mths

$\begin{array}{ll}0 & 0 \\ 0 & 0 \\ 0 & 0\end{array}$

$12-18 \mathrm{~m}$

$\begin{array}{lr}0 & 18-24 \\ 0 & 0 \\ 0 & 0\end{array}$

5) Research (basic science)

6) How many inpatient training sites do your fellows rotate at?
$\bigcirc 1 \bigcirc 2$
$\bigcirc 4$
5 or more

$\bigcirc 3$

7) What are the types of inpatient training sties that your fellows rotate at? Please select all that apply.

$\square$ Academic Medical Center

$\square$ VA

$\square$ Public (city/county/state)

$\square$ Community

$\square$ Military

$\square$ HMO

$\square$ Other 


\section{Confidential}

8) What is the primary site of inpatient training in your fellowship program?

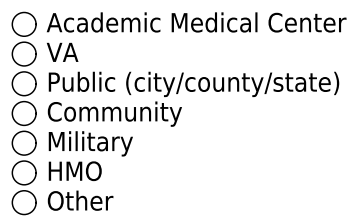

\section{INPATIENT TRAINING SITE MODEL}

9) Including all training sites, what type(s) of inpatient team(s) do your fellows rotate on? Please select all that apply.

GENERAL GI CONSULT TEAM (fellows work with a Gl attending to serve teams requesting consultation on their admitted patients, who are under the care of a non-GI attending)

$\square$ DISEASE-SPECIFIC GI CONSULT TEAM (fellows work with a GI subspecialty attending to serve teams requesting consultation on their admitted patients, based on specific disease conditions such as IBD or liver)

$\square$ GENERAL GI ADMITTING TEAM (fellows rotate on an admitting team of assigned inpatients with any GI condition and staffed by a Gl attending +/- medicine housestaff, nurse practitioners, physician assistants)

$\square$ DISEASE-SPECIFIC GI ADMITTING TEAM (fellows rotate on an admitting team of assigned inpatients specific to a GI disease condition, such as IBD or liver, staffed by a GI subspecialty attending +/- medicine housestaff, nurse practitioners, physician assistants)

10) What is the predominant type of inpatient training experience for your fellows at your primary site of training?

General GI consult team

Disease-specific GI consult team

General GI admitting team

$\bigcirc$ Disease-specific $\mathrm{Gl}$ admitting team

\section{GI FELLOW INPATIENT EXPERIENCE}

11) If housestaff or mid-level providers have a question regarding the clinical management of a patient on the $\mathrm{Gl}$ inpatient service, with whom do they most often discuss the case?

GI Fellow

Gl Attending

Both equally 


\section{Confidential}

In your program, how important are the following inpatient fellow responsibilities to ensure proper running of the inpatient service? Please rank from most important (1) to least important (6); answers cannot be used more than once.

12) Lead clinical rounds

13) Perform endoscopic procedures on inpatients

14) Complete inpatient documentation (e.g. admit/consult notes, procedure notes, etc.)

15) Organize teaching (for co-fellows, housestaff and/or medical students)

16) Communicate with outpatient $\mathrm{Gl}$ providers of inpatients

17) Schedule outpatient GI follow-up appointments

$\begin{array}{llllll}1 & 2 & 3 & 4 & 5 & 6 \\ 0 & 0 & 0 & 0 & 0 & 0 \\ 0 & 0 & 0 & 0 & 0 & 0\end{array}$

18) At your primary site of training, do fellows serve as the responding clinician (i.e. responsible for direct care of inpatients, including daily orders, discharge paperwork, etc.) on any of the Gl services?

Yes

No

In your program, how important are the following skills for fellows to develop during their inpatient service time? Please rank from most important (1) to least important (8); answers cannot be used more than once.

19) Efficiency in completing inpatient tasks

20) Interviewing patients

21) Physical exam

22) Oral presentation

23) Utilizing medical literature to inform decision-making

24) Clinical decision-making

25) Performing endoscopy

26) Communicating effectively with patients, families, and team members

\begin{tabular}{|c|c|c|c|c|c|c|}
\hline${ }^{1}$ & ${ }^{2}$ & $3^{3}$ & $4^{4}$ & $\stackrel{5}{\bigcirc}$ & ${ }^{6}$ & ${ }^{7}$ \\
\hline 0 & 0 & 0 & 0 & 0 & 0 & 0 \\
\hline 0 & 0 & 0 & 0 & $\bigcirc$ & 0 & 0 \\
\hline 0 & 0 & 0 & 0 & 0 & 0 & 0 \\
\hline 0 & 0 & 0 & 0 & 0 & 0 & 0 \\
\hline 0 & 0 & 0 & 0 & 0 & 0 & 0 \\
\hline 0 & 0 & 0 & 0 & 0 & 0 & 0 \\
\hline 0 & 0 & 0 & 0 & 0 & 0 & 0 \\
\hline
\end{tabular}


Confidential

Page 4 of 5

27) After a fellow initially evaluates a new consult or new admission to the Gl service, what percentage of the time does the fellow return to the bedside with the attending to evaluate the patient together?
$100 \%$ of the time
$75 \%$ of the time
$50 \%$ of the time
$25 \%$ of the time
$\bigcirc 0 \%$ of the time

28) For the same scenario above, what percentage of the time time does the entire team (attending, co-fellows, and any rotating housestaff/medical students) return to the bedside together to evaluate the patient?

$\bigcirc 100 \%$ of the time $\bigcirc 75 \%$ of the time $\bigcirc 50 \%$ of the time $\bigcirc 25 \%$ of the time $\bigcirc 0 \%$ of the time

\section{GI FELLOW INPATIENT EDUCATION}

29) On a typical day on service at the primary site of inpatient training, how much time do Gl attendings set aside to teach fellows and any other members of the team?
$\bigcirc \geq 60$ minutes
30-60 minutes
$15-30$ minutes
$\bigcirc<15$ minutes
$\bigcirc$ minutes

30) On a typical day on service at the primary site of inpatient training, how much time do fellows spend teaching other members of the team?
$\bigcirc \geq 60$ minutes
30-60 minutes
15-30 minutes
$\bigcirc<15$ minutes
$\bigcirc$ minutes

\section{How often do inpatient fellows participate in the following educational activities?}

31) Review relevant inpatient

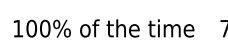
radiology studies with a radiologist

32) Review relevant inpatient pathology specimens with a pathologist

33) Attend academic conferences (e.g. Gl grand rounds)

$\begin{array}{ll}\bigcirc & 0 \\ 0 & 0\end{array}$
$50 \%$ of the time $25 \%$ of the time $0 \%$ of the time

4) For fellows rotating on the inpatient service(s), the amount of time dedicated to education is:
Far too much
Too much
About right
Too little
Far too little

\section{PROGRAM DIRECTOR-SPECIFIC QUESTIONS}

35) How often do inpatient fellows at the primary site of training violate duty hour limits?
$100 \%$ of the time
$75 \%$ of the time
$50 \%$ of the time
$25 \%$ of the time
$0 \%$ of the time

36) How often do the inpatient fellows feel overworked at your primary site of training?
$100 \%$ of the time
$75 \%$ of the time
$50 \%$ of the time
$25 \%$ of the time
$0 \%$ of the time 


\section{Confidential}

37) How often do inpatient attendings sit down with fellows at the conclusion of their rotations to discuss feedback?
$100 \%$ of the time
$75 \%$ of the time
$50 \%$ of the time
$25 \%$ of the time
$0 \%$ of the time

38) During the entire fellowship, the amount of time that fellows spend on the inpatient service(s) is:

$\bigcirc$ Far too much $\bigcirc$ Too much $\bigcirc$ About right $\bigcirc$ Too little $\bigcirc$ Far too little

39) Inpatient training is an important part of Gl fellowship training

$\bigcirc$ Strongly agree $\bigcirc$ Agree $\bigcirc$ Neutral $\bigcirc$ Disagree $\bigcirc$ Strongly disagree

40) I am satisfied with the quality of care that our fellows provide for inpatients.

$\bigcirc$ Strongly agree $\bigcirc$ Agree $\bigcirc$ Neutral $\bigcirc$ Disagree $\bigcirc$ strongly disagree

\section{Please rate the overall quality of your fellowship program's:}

41) Inpatient training experience

Very good

$\bigcirc$

42) Education on the wards (e.g. attending-led bedside teaching or prepared lectures)

43) Education from academic conferences (e.g. Gl grand rounds)

44) Feedback from $\mathrm{Gl}$ attendings on fellows' inpatient performance

$\bigcirc$

$\bigcirc$

Good
$\bigcirc$

Acceptable
$\bigcirc$

$\begin{array}{cc}\text { Poor } & \text { Very poor } \\ \bigcirc & \bigcirc \\ 0 & \bigcirc\end{array}$

$\bigcirc$

$\bigcirc$

45) If possible, please provide your program's percentile rank on the 2015 AGA GTE (Gastroenterology Training Exam) for fellows in YEAR 1 of training. Note - this score is found on page 4 of the GTE Score Report.

46) If possible, please provide your program's percentile rank on the 2015 AGA GTE (Gastroenterology Training Exam) for fellows in YEAR 2 of training. Note - this score is found on page 4 of the GTE Score Report.

47) If possible, please provide your program's percentile rank on the 2015 AGA GTE (Gastroenterology Training Exam) for fellows in YEAR 3 of training. Note - this score is found on page 4 of the GTE Score Report.

48) OPTIONAL: Do you have any suggestions on how to improve the inpatient training experience of Gl fellows?

49) OPTIONAL: If you have any other comments, please share them here. 


\section{Appendix 2}

Confidential

\section{Fellow Survey}

Page 1 of 5

Please complete the survey below.

Thank you!

\section{GI FELLOWSHIP PROGRAM INFORMATION:}

1) What is your gender?

Male

$\bigcirc$ Female

2) What is your year of fellowship training?

1st year

2nd year

$\bigcirc$ 3rd year

3) What is your fellowship training track?

Clinical (not research-focused)

Research (clinical)

$\bigcirc$ Research (basic science)

4) How many Gl fellows (1st - 3rd years) are in your program currently?

5) How much time do you spend on the inpatient service over the duration of your 3-year fellowship program?
$0-6$ mths
6-12 mths
$12-18$ mths
$18-24$ mths
24-30 mths
30-36 mths

6) How many inpatient trainee sites do you rotate at?

$\bigcirc 1 \bigcirc 2 \bigcirc 3 \bigcirc 4 \bigcirc 5$ or more

7) What are the types of inpatient trainee sites that you rotate at? Please select all that apply.

$\square$ Academic Medical Center

$\square$ VA

Public (city/county/state)

$\square$ Community

$\square$ Military

$\square$ HMO

$\square$ Other

8) What is the primary site of inpatient training in your fellowship program?

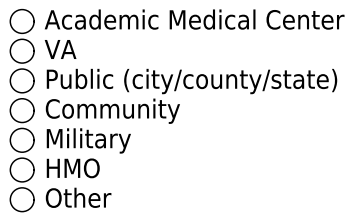


Confidential

INPATIENT TRAINING SITE MODEL

9) Including all training sites, what type(s) of inpatient team(s) do you rotate on? Please select all that apply.

$\square$ GENERAL GI CONSULT TEAM (fellows work with a GI attending to serve teams requesting consultation on their admitted patients, who are under the care of a non-GI attending)

$\square$ DISEASE-SPECIFIC GI CONSULT TEAM (fellows work with a GI subspecialty attending to serve teams requesting consultation on their admitted patients, based on specific disease conditions such as IBD or liver)

$\square$ GENERAL GI ADMITTING TEAM (fellows rotate on an admitting team of assigned inpatients with any GI condition and staffed by a Gl attending + /- medicine housestaff, nurse practitioners, physician assistants) $\square$ DISEASE-SPECIFIC GI ADMITTING TEAM (fellows rotate on an admitting team of assigned inpatients specific to a GI disease condition, such as IBD or liver, staffed by a GI subspecialty attending +/- medicine housestaff, nurse practitioners, physician assistants)

10) What is the predominant type of inpatient training experience at your primary site of training?

General GI consult team

$\bigcirc$ Disease-specific GI consult team

General Gl admitting team

$\bigcirc$ Disease-specific Gl admitting team

\section{GI FELLOW INPATIENT EXPERIENCE}

11) If housestaff or mid-level providers have a question regarding the clinical management of a patient on the $\mathrm{Gl}$ inpatient service, do they typically discuss the case with you or the $\mathrm{Gl}$ attending?

Gl fellow

$\mathrm{Gl}$ attending

Both equally

\section{In your program, how important are the following inpatient fellow responsibilities to ensure proper running of the inpatient service? Please rank from most important (1) to least important (6); answers cannot be used more than once.}

12) Lead clinical rounds

13) Perform endoscopic procedures on inpatients

14) Complete inpatient documentation (e.g. admit/consult notes, procedure notes, etc.)

15) Organize teaching (for co-fellows, housestaff and/or medical students)

16) Communicate with outpatient $\mathrm{Gl}$ providers

1

O

O

$\bigcirc$

○

$\bigcirc$

17)

$$
2
$$

3

\section{4}

$$
\bigcirc
$$

${ }^{5}$

6

0 
Confidential

Page 3 of 5

Schedule outpatient GI follow-up appointments

18) At your primary site of training, do you serve as the responding clinician (i.e. responsible for direct care of inpatients, including daily orders, discharge paperwork, etc.) on any of the GI services?

Yes $\bigcirc$ No

In your program, how important are the following skills for fellows to develop during their inpatient service time? Please rank from most important (1) to least important (8); answers cannot be used more than once.

19) Efficiency in completing inpatient tasks

20) Interviewing patients

21) Physical exam

22) Oral presentation

23) Utilizing medical literature to inform decision-making

24) Clinical decision-making

25) Performing endoscopy

26) Communicating effectively with patients, families, and team members

$\begin{array}{llllllll}1 & 2 & 3 & 4 & 5 & 6 & 7 & 8 \\ 0 & 0 & 0 & 0 & 0 & 0 & 0 & 0\end{array}$

27) After you initially evaluate a new consult or new admission to the team, what percentage of the time do you return to the bedside with your $\mathrm{Gl}$ attending to evaluate the patient together?
$100 \%$ of the time
$75 \%$ of the time
$50 \%$ of the time
$25 \%$ of the time
$0 \%$ of the time

28) For the same scenario above, what percentage of the time does the entire team (attending, co-fellows, and any rotating housestaff/medical students) return to the bedside together to evaluate the patient?
$100 \%$ of the time
$75 \%$ of the time
$50 \%$ of the time
$25 \%$ of the time
$0 \%$ of the time

\section{GI FELLOW INPATIENT EDUCATION}

29) On a typical day on service at the primary site of inpatient training, how much time do your Gl attendings set aside to teach you and any other members of the team?
$\bigcirc \geq 60$ minutes
30-60 minutes
15-30 minutes
$0<15$ minutes
0 minutes 


\section{Confidential}

30) On a typical day on service at the primary site of inpatient training, how much time do you spend teaching other members of your team?
$0 \geq 60$ minutes
30-60 minutes
$15-30$ minutes
$0<15$ minutes
0 minutes

\section{How often do you participate in the following educational activities while on the inpatient service?}

31) Review relevant inpatient

$100 \%$ of the time $75 \%$ of the time $50 \%$ of the time radiology studies with a radiologist

32) Review relevant inpatient pathology specimens with a pathologist

33) Attend academic conferences (e.g. Gl grand rounds)

34) While rotating on your inpatient service(s), the amount of time dedicated to education is:

$\bigcirc$ Far too much $\bigcirc$ Too much $\bigcirc$ About right $\bigcirc$ Too little $\bigcirc$ Far too little

\section{FELLOW-SPECIFIC QUESTIONS}

35) On a typical day on service at your primary site of inpatient training, how many inpatients are you assigned to take care of?
20 or more
$\bigcirc 16-20 \bigcirc 11-15$
6-10
0-5

36) How often do you violate duty hour limits as the inpatient fellow at your primary site of training?

100\% of the time $\bigcirc 75 \%$ of the time $\bigcirc 50 \%$ of the time $\bigcirc 25 \%$ of the time $\bigcirc 0 \%$ of the time

37) How often do you feel overworked as the inpatient fellow at your primary site of training?

$\bigcirc 100 \%$ of the time $\bigcirc 75 \%$ of the time $\bigcirc 50 \%$ of the time $\bigcirc 25 \%$ of the time $\bigcirc 0 \%$ of the time

38) How often do inpatient attendings sit down with you at the conclusion of your rotations to discuss feedback?

100\% of the time $\bigcirc 75 \%$ of the time $\bigcirc 50 \%$ of the time $\bigcirc 25 \%$ of the time $\bigcirc 0 \%$ of the time

39) During your entire fellowship, the amount of time that you spend on the inpatient service(s) is:

$\bigcirc$ Far too much $\bigcirc$ Too much $\bigcirc$ About right $\bigcirc$ Too little $\bigcirc$ Far too little

40) Inpatient training is an important part of Gl fellowship training.

$\bigcirc$ Strongly agree $\bigcirc$ Agree $\bigcirc$ Neutral $\bigcirc$ Disagree $\bigcirc$ Strongly disagree 


\section{Confidential}

41) I am satisfied with the quality of care that I provide for inpatients.

$\bigcirc$ Strongly agree $\bigcirc$ Agree $\bigcirc$ Neutral $\bigcirc$ Disagree $\bigcirc$ Strongly disagree

For my inpatient training experience, I would prefer rotating on a:

42) General GI consult team

43) Disease-specific Gl consult team

44) General Gl admitting team

45) Disease-specific Gl admitting team

$\begin{array}{cc}\text { Strongly Agree } & \text { Agree } \\ \bigcirc & \bigcirc \\ \bigcirc & \bigcirc \\ \bigcirc & \bigcirc \\ \bigcirc & \bigcirc\end{array}$

Neutral
$\bigcirc$
$\bigcirc$
$\bigcirc$

$\begin{array}{cc}\text { Disagree } & \text { Strongly } \\ \bigcirc & \text { Dis@gree } \\ \bigcirc & \bigcirc \\ \bigcirc & \bigcirc \\ \bigcirc & \bigcirc\end{array}$

Please rate the overall quality of your:

46) Inpatient training experience

$\begin{array}{cc}\text { Very good } & \text { Good } \\ 0 & \end{array}$

Good Acceptable Poor

47) Education on the wards (e.g. attending-led bedside teaching

O $O$
or prepared lectures)

48) Education from academic conferences (e.g. Gl grand rounds)

49) Feedback from your GI attendings on your inpatient performance 


\section{References}

1. American Association for the Study of Liver Diseases, American College of Gastroenterology, American Gastroenterological Association (AGA) Institute, et al. The Gastroenterology Core Curriculum, Third Edition. Gastroenterology. 2007;132: 2012-2018.

2. Haferbecker D, Fakeye O, Medina SP, et al. Perceptions of educational experience and inpatient workload among pediatric residents. Hosp Pediatr. 2013;3:276-284.

3. Arora VM, Georgitis E, Siddique J, et al. Association of workload of on-call medical interns with on-call sleep duration, shift duration, and participation in educational activities. JAMA. 2008;300:1146-1153.

4. Haney EM, Nicolaidis C, Hunter A, et al. Relationship between resident workload and self-perceived learning on inpatient medicine wards: a longitudinal study. BMC Med Educ. 2006;6:35.

5. Guardino JM, Proctor DD, Lopez R, et al. Utilization of and adherence to the gastroenterology core curriculum on hepatology training during a gastrointestinal fellowship. Clin Gastroenterol Hepatol. 2008;6:682-688.e2.

6. Saha S, Roberson E, Richie K, et al. Women's health training in gastroenterology fellowship: a national survey of fellows and program directors. Dig Dis Sci. 2011;56:751-760.

7. Jirapinyo P, Hunt RS, Tabak YP, et al. Global health education in gastroenterology fellowship: a national survey. Dig Dis Sci. 2016;61:3443-3450.

8. Dotson JL, Falaiye T, Bricker JB, et al. North American pediatric gastroenterology fellowship needs assessment in inflammatory bowel disease: trainee and program director perspectives. Inflamm Bowel Dis. 2016;22:1616-1620.
9. AMA Residency and Fellowship Database. https://www.amaassn.org/life-career/search-ama-residency-fellowship-database.

10. American College of Gastroenterology GI Fellowship Programs. http://gi.org/fellows-in-training/gi-fellowship-programs.

11. Harris PA, Taylor R, Thielke R, et al. Research electronic data capture (REDCap) - a metadata-driven methodology and workflow process for providing translational research informatics support. J Biomed Inform. 2009;42:377-381.

12. Lubke G, Muthen B. Applying multigroup confirmatory facto models for continuous outcomes to Likert scale data complicates meaningful group comparisons. Struct Equ Model. 2004;11: 514-534.

13. Chapman AL, Hadfield M, Chapman CJ. Qualitative research in healthcare: an introduction to grounded theory using thematic analysis. J R Coll Physicians Edinb. 2015;45:201-205.

14. Srinivasan M, Li ST, Meyers FJ, et al. "Teaching as a competency": competencies for medical educators. Acad Med. 2011;86: 1211-1220.

15. Holmboe ES, Ward DS, Reznick RK, et al. Faculty development in assessment: the missing link in competency-based medical education. Acad Med. 2011;86:460-467.

16. Patel SG, Keswani R, Elta G, et al. Status of competency-based medical education in endoscopy training: a nationwide survey of US ACGME-accredited gastroenterology training programs. Am J Gastroenterol. 2015;110:956-962.

17. Liebman SE, Moore CA, Monk RD, et al. What are we doing? A survey of United States Nephrology Fellowship Program Directors. Clin J Am Soc Nephrol. 2017;12:518-523.

18. Kaplowitz MD, Hadlock TD, Levine R. A comparison of web and mail survey response rates. Public Opin Q. 2004;68:94-101. 